\title{
Desafios e possibilidades do método de educação popular na escola pública
}

Thaís Gonçalves Saggiomo, Michele Silveira Azevedo², Vanessa Gonçalves Dias³, Patricia Rutz Bierhals ${ }^{4}$

\begin{abstract}
Resumo
O artigo parte de reflexões e debates mais amplos realizados nos seguintes seminários: Fundamentos da Educação Popular I e Educação Popular na Escola Pública II, no Programa de Pós-Graduação da Universidade Federal de Pelotas - FaE/ PPGE/UFPel. E tem por objetivo central refletir sobre as possibilidades de desenvolvimento do método de educação popular no contexto da escola pública. Para tanto, dialogamos ao longo deste ensaio com autores, como: Marx (1978), Freire (1987), Mészáros (2008), Paludo (2012; 2015), Frigotto (1985; 2002). Caracteriza-se enquanto um estudo de revisão teórica, sua perspectiva teórico-metodológica de abordagem da realidade é o materialismo histórico dialético, tendo como base os autores: Kosik (1995) e Triviños (1987). Na conclusão, argumenta-se que ao evidenciarmos o ambiente escolar como um espaço de potencialidades pedagógicas, reafirmase neste, que o diálogo como instrumento político, quando articulado à práxis educativa num horizonte democrático, possibilita campo fértil no desafio de aproximar a educação popular como um método de trabalho no/do contexto da educação escolar.
\end{abstract}

\section{Palavras-chave}

Método. Educação Popular. Escola Pública. Movimentos Sociais.

1. Doutoranda em Educação Ambiental na Universidade Federal do Rio Grande, Rio Grande do Sul, Brasil. E-mail: thaisfurg@yahoo.com.br.

2. Mestra em Educação pela Universidade Federal de Pelotas, Rio Grande do Sul, Brasil. E-mail: michelesilveiraazevedo@gmail.com.

3. Doutoranda em Educação na Universidade Federal do Rio Grande do Sul, Brasil. E-mail: vanygd@yahoo.com. br.

4. Doutoranda em Educação na Universidade Federal do Rio Grande do Sul, Brasil. E-mail: patriciabierhals@ yahoo.com.br. 


\title{
Challenges and possibilities ofthe popular education method in the public school
}

Thaís Gonçalves Saggiomo*, Michele Silveira Azevedo**, Vanessa Gonçalves Dias ${ }^{* * *}$, Patricia Rutz Bierhals****

\begin{abstract}
The article parts from broader reflections and discussions in the seminars: Popular Education fundamentals I and Popular Education in the Public School II, in the Federal University of Pelotas' Post-graduation program - FaE/ PPGE/UFPel (acronyms in Portuguese). And it has as the central objective the reflection about the possibilities of development of a Popular Education method in the Public school context. Therefore, we dialogue through this essay with authors like Marx (1978), Freire (1987), Mézáros (2008), Paludo (2012; 2015). Frigotto (1985; 2002). It characterizes itself while a theoretical study, its methodological-theoretical perspective of reality's approach is the dialectical materialism, being based on the authors: Kosik (1995) and Triviños (1987). In the conclusion section, it's discussed that while we evidence the school environment as a pedagogical potentialities' space, it reaffirms itself in this, that the dialogue as a political instrument, when it is articulated with the education praxis in the democratic horizon, it enables a productive field in the challenge of approaching the popular education as a job method in/of the context of schooling.
\end{abstract}

\section{Keywords}

Method. Popular Education. Public School. Social Movements.

\footnotetext{
*PhD student in Education, Federal University of Rio Grande, State of Rio Grande do Sul, Brazil. E-mail: thaisfurg@ yahoo.com.br.

* Master in Education, Federal University of Pelotas, State of Rio Grande do Sul, Brazil. E-mail: michelesilveiraazevedo@gmail.com.

*** PhD student in Education, Federal University of Rio Grande do Sul, State of Rio Grande do Sul, Brazil. E-mail: vanygd@yahoo.com.br.

**** PhD student in Education, Federal University of Rio Grande do Sul, State of Rio Grande do Sul, Brazil. E-mail: patriciabierhals@yahoo.com.br.
} 


\section{Introdução}

Problematizar e construir as possibilidades de educação popular no contexto da escola pública é bastante complexo, e exige-nos uma imersão na historicidade que compõe a trajetória da educação popular e da escola pública. Neste processo, a busca pelos entremeios de oportunidade, manutenção ou resistência e proposição de novas possibilidades de trabalho no "chão da escola" apresentase como um caminho em construção e em constante diálogo com os desafios legais e ideológicos de nossa frágil democracia.

Nesses meandros investigativos, nos desafiamos a revisitar o histórico de lutas que compõem as práticas de educação popular (EP) no Brasil, de forma a evidenciar as raízes que constituem o método de educação e as marcas que foram sendo registradas no escopo do acúmulo teórico/prático, e nos marcos legais por intelectuais que foram se constituindo, ao passo que organizavam os processos de EP junto às classes populares. Assim, o artigo pretende, a partir do materialismo histórico e dialético, refletir sobre as possibilidades de desenvolvimento do método de educação popular no contexto da escola pública, evidenciando as possíveis convergências entre diálogos pedagógicos, tanto nas práticas de EP, quanto nas conquistas que se materializam no cotidiano institucionalizado da escola pública.

Cabe registrarmos a compreensão de que, ao evidenciarmos a formação histórica, cultural e política desses processos, também trataremos de antagonismos e discrepâncias enraizadas nas próprias contradições da formação social brasileira, na qual a existência da exploração e alienação da classe trabalhadora estrutura-se dentro e fora dos muros escolares. Sob a hegemonia do sistema capitalista, os condicionamentos ideológicos nas últimas décadas ultrapassam as "barreiras" locais, através da reestruturação produtiva global do trabalho (ANTUNES, 2011).

A manutenção dessa força ideológica é composta por estruturas legitimadas pela lei, pela cultura socioeconômica e pela força do aparato estatal. Dessa forma, assumimos a compreensão de que o Estado é o comitê da burguesia, conforme já afirmava Marx (1978), assim como compreendemos, a partir da perspectiva gramsciana, ser um desafio para a classe trabalhadora disputar e avançar em um projeto contra hegemônico, mobilizando-se por meio de estratégias necessárias para que o Estado assuma a condição democrática e desenvolva-se enquanto instrumento da classe trabalhadora.

Embora a escola pública tenha em sua "função" ideológica o comprometimento em responder às demandas do capital, como ressalta Frigotto (2002, p. 224) : “a improdutividade da escola, dentro das relações capitalistas de produção, torna-se produtiva na medida em que a escola é desqualificada para a classe dominada, para os filhos dos trabalhadores". Nesse debate, também é possível afirmar que a escola, enquanto território em disputa das classes populares, pode se constituir como espaço de práticas de resistência, encontro e inovação popular.

Resgatando Paulo Freire (1987), situamos na escola a potencialidade de um espaço que abrange pedagogias e currículos em disputa, desde o tecnicista e bancário ao dialógico e libertário. Assim, podemos identificar no chão da escola, em suas diferentes esferas, brechas e tensões outorgadas formal ou informalmente pela atuação presente da EP, na comunidade, nos professores, nos funcionários e no seu próprio processo de luta pela garantia institucional de uma educação de qualidade para todos. Na mesma perspectiva analítica, Vale (1996, p. 57) destaca o seguinte:

A Educação Popular por nós entendida é necessariamente uma educação de classe. 
Uma educação comprometida com os segmentos populares da sociedade, cujo objetivo maior deve ser o de contribuir para a elevação da sua consciência crítica, do reconhecimento da sua condição de classe e das potencialidades transformadoras inerentes a essa condição.

Nessa perspectiva, a EP se estrutura na proposição de rompimento com uma educação comprometida com a formação de sujeitos condicionados pelas leis do mercado. Situação que condiciona e limita o ambiente escolar no desenvolvimento do processo educativo que oportunize aos educandos encontrarem-se no e com o mundo na totalidade de sua existência humana. Nesse sentido, é fundamental compreendermos que o diálogo com o mundo do trabalho, conforme salienta Frigotto (1985, p. 2),

é parte fundamental da ontologia do ser social. A aquisição da consciência se dá pelo trabalho, pela ação sobre a natureza. $\mathrm{O}$ trabalho, neste sentido, não é emprego, não é apenas uma forma histórica do trabalho em sociedade, ele é a atividade fundamental pela qual o ser humano se humaniza, se cria, se expande em conhecimento, se aperfeiçoa. O trabalho é a base estruturante de um novo tipo de ser, de uma nova concepção de história.

A partir dessa compreensão é que a concepção de trabalho como princípio educativo (FRIGOTTO, 2002; FRIGOTTO; CIAVATTA; RAMOS, 2005) toma por base o trabalho socialmente útil (FREITAS, 2009). É isso que teoricamente irá diferenciar as propostas da escola capitalista da proposta da educação que tem como horizonte a omnilateralidade. Então, essa articulação entre a organização do trabalho pedagógico e a centralidade da categoria trabalho, que historicamente a EP promove em suas estratégias de resistência no interior dos movimentos sociais e em suas experiências educativas, consequentemente encontra eco na escola. Diante desse antagonismo histórico é que a construção reflexiva deste artigo nos conduz a um esforço teórico e prático sobre o tema em questão. Para tanto, sistematizamos pontos importantes que compreendemos serem dispositivos reflexivos que mobilizam as possibilidades efetivas da educação popular na escola pública, sendo elas: a) predominância dos filhos e filhas da classe trabalhadora nos bancos escolares da rede pública; b) excelência da categoria professoral como sujeitos que constituem a classe trabalhadora; c) disputa ideológica que se evidencia nas relações entre a comunidade escolar; d) opressão garantida pelos mecanismos de controle do sistema educacional; e) necessidade de se encontrar um novo horizonte, para que se possa dar continuidade num processo formativo comprometido com a transformação de sujeitos e do mundo.

Assim, desenvolvemos o conteúdo deste trabalho a partir da compreensão de que esses dispositivos carregam em si os pilares motivacionais para que se justifique o esforço construído na busca por um caminho possível, em um tempo histórico em que os retrocessos políticos estreitam as nossas brechas, e o avanço da ideologia neoliberal nos coloca como desafio epistemológico a construção de conhecimentos necessários para reconstrução de estratégias capazes de garantir a produção das conquistas populares no chão da escola pública.

Abordamos neste texto, sem ingenuidade, as contradições presentes desde a adequação da escola pública ao movimento organizado pela EP. Nele compreendemos que, sendo a escola pública de acesso à classe popular, é possível constituir-se como espaço de luta entre a manutenção da hegemonia burguesa capitalista e a ocupação de proposição popular.

Nesse sentido, cabe ressaltar que as lutas dos movimentos sociais, associadas ao momento de abertura política promovem no Brasil uma atmosfera democrática, impulsionando, a partir da Constituição Federal, em 1988, a educação popular no contexto 
da escola pública, provocando uma tensão no Estado que culminou na construção de políticas, na alteração da proposta de gestão, e principalmente no acesso universal ao ensino fundamental para toda população brasileira. Processo, que por si só, não significa garantia da formação comprometida com a classe trabalhadora, mas amplia o espaço de disputa.

\section{A educação popular e suas interfaces no projeto de desenvolvimento}

A educação popular, de acordo com Paludo (2012), inicia sua gestão com o projeto de modernidade brasileiro. Teve sua afirmação no interior do campo democrático e popular, como uma nova concepção e práticas de educação ou "qualificação humana" nos anos de 1970 e 1980 pelas conexões entre intelectuais orgânicos e as classes populares. Mesmo que se tenha conhecimento de práticas anteriores a esse período, cabe citar que, como todo foco de organização popular no Brasil anterior ao Golpe Civil Militar de 1964, foi silenciado com práticas de violência militar que se estenderam por quase duas décadas.

Desse período, podemos citar a exemplo das experiências de educação popular, o Movimento de Alfabetização (MOVA) que estabeleciacomo práticadeensino/aprendizagem os Círculos de Cultura, que se constituíam como espaço para o desenvolvimento do método de alfabetização de Paulo Freire. Após o golpe, o MOVA, foi substituído pelo Movimento Brasileiro de Alfabetização (MOBRAL), e nesse movimento toda proposição de reformas que antecediam ao golpe tornam-se alvo de uma política autoritária e violenta que intencionava a desarticulação das massas em todas as suas bandeiras de luta. Nesse método, o processo de ensino/aprendizado, baseado na formação de sujeitos capazes não só de codificar símbolos, mas também de decodificá-los em um movimento de construção autêntica de sua palavra, foi reduzido à reprodução quase desenhada dos símbolos e, no aprimoramento dessa educação, o diálogo transformou-se em transmissão, a palavra autêntica perdeu a identidade popular e os alunos passaram a silenciar suas necessidades, sendo conduzidos a (re)produzir o conteúdo e a forma do ensino adequado às necessidades do mercado.

Assim, gradativamente, o regime civil militar vai constituindo, na escola pública, uma proposta de educação coerente com seu projeto societário. Dentre suas estratégias, a figura de inspetor pedagógico articulada à dura hierarquizaçãodadireçãoescolarsedestacacomo instrumento de fiscalização e monitoramento contínuo. O controle sob os recursos e a falta de autonomia no trabalho docente, também fizeram parte desse processo. Cabe destacar que essa prática interventiva, ao passo que desarticulava o método de educação popular, impunha às práticas escolares o enraizamento de uma educação tecnicista e bancária. Nesse marco, acentua-se a percepção de educação e mercado e, entre público e privado, a escola pública assume cada vez mais um público bem definido: filhos e filhas da classe trabalhadora.

Esse processo contribui para demarcação de dois grandes territórios no campo da educação brasileira: o formal institucionalizado e monitorado pela legislação e pelas estratégias de fiscalização e monitoramento pedagógico; o não formal, que se forja no campo democrático popular e vai tomando amplitude na mobilização e organização da classe trabalhadora em luta por melhores condições de existência.

Esses terrenos antagônicos constituem o cerne da correlação de forças entre o Estado brasileiro e o movimento social. Nessa dualidade, o Estado, mesmo pós-ditadura, permanece comprometido com um projeto de desenvolvimento neoliberal, assumindo seu lugar na teia do desenvolvimento desigual e combinado, produzido pela lógica do sistema capitalista globalizado. Parte dos movimentos 
sociais, com a abertura do regime político nos anos 1970 e 1980, mobilizam-se em prol da constituinte e demarcam sua posição comprometida com o desafio de assumir, no seu cotidiano, a luta por um projeto societário que tenha como horizonte a emancipação humana.

Nessa perspectiva, não se tratava somente de fazer para o povo, nem de entendê-la como educação escolar do povo, métodos e técnicas, cultura popular, saber das comunidades, educação de jovens e adultos ou educação permanente (BRANDÃO, 2002). É no interior do "Movimento de Educação Popular", que acontece no interior do "movimento político e sociocultural mais amplo", que vai sendo formulada a "concepção de Educação Popular" e esse mesmo Movimento também se constituía como formador, porque propiciava, na dinâmica política e organizativa dos diferentes movimentos sociais, a vivência concreta de outro modo de relações sociais e de compreensão da realidade. (PALUDO, 2015, p. 227).

Aqui, podemos demarcar um possível encontro entre educação popular e a escola pública, no qual, também se manifesta nosso primeiro ganho enquanto movimento que disputa o território institucionalizado da educação formal. A materialidade da Constituição Federal de 1988 carrega em si uma das maiores mobilizações em defesa da educação pública e de qualidade para todos. Pela primeira vez no marco legal do país, a educação ocupa um lugar de direito popular, de dever do Estado, e tem como finalidade a formação dos sujeitos.

Nesse marco legal, também podemos observar o reconhecimento da escola pública como instrumento chave no projeto de desenvolvimento de uma sociedade democrática. Nesse sentido, além de deliberar sobre a função e finalidade desse espaço, reconhece que a construção de um Estado Democrático por direito, passa pela (re) definição da escola, como organização democrática e, nesse movimento, delibera- se sobre os princípios da gestão democrática; a valorização dos professores e demais profissionais atuantes na escola; a liberdade de ensino e de aprendizagem; a garantia de acesso e permanência etc. Destes princípios, a compreensão do caráter público da educação, a formação continuada dos professores e a garantia do ensino público e gratuito, articulado à gestão democrática e à promoção do plano nacional, instituem um novo tempo no chão da escola.

Os movimentos sociais organizados conquistaram espaços estratégicos que, nestes últimos anos, foram se materializando como ferramentas de diálogo e, quando apropriados pela comunidade escolar, instrumentos de transformação e recondução. Por esse pressuposto, a escola construída na manipulação e no antidiálogo, agora em movimentos lentos, porém contínuos, deflagra-se enquanto território de disputa e de possibilidades populares. Conforme Paludo (2015, p. 227):

\begin{abstract}
As expressões de povo sujeito de sua história, autonomia, conscientização, organização, protagonismo popular, luta e transformação indicavam a orientação das práticas, assim como o "fazer com", trabalhado conceitualmente como práxis e por vezes como o movimento permanente entre prática-teoria-prática, ver-julgar-agir ou ação-reflexão-ação, era considerado a lógica metodológica, permeada pela relação entre os saberes populares e o conhecimento historicamente acumulado, pela sistematização, pela pesquisa-ação participante e pelo diálogo, que orientava os métodos, técnicas e procedimentos, incluindo os processos avaliativos, dos múltiplos processos e práticas educativas que se instauraram na América Latina.
\end{abstract}

Assim, sem cairmos no tradicional romantismo pedagógico - cabe o registro da intenção à construção, da construção à efetiva participação popular - na historicidade dos anos 1990 aos anos 2000, podemos evidenciar que, entre os duelos travados, o que mais podemos 
encontrar entre as práticas escolares é a presença do método de educação popular, construído em meio às contradições que favorecem tanto a articulação quanto a desarticulação deste no desenvolvimento das ações educativas. Dentro dessa perspectiva, Leher (2007, p. 24) afirma o seguinte:

A retomada das discussões sobre a educação popular foi colocada em pauta pelos movimentos sociais. As contradições ensejadas pelas políticas de "ajuste estrutural" neoliberal provocaram relativa ascensão das lutas sociais, assim como recolocaram na agenda dos movimentos sociais a necessidade de repensar suas estratégias. Nesse contexto é possível verificar um extraordinário revigoramento da educação popular e, em particular, da formação política. Examinando a experiência latino-americana, em especial a luta dos povos originários (Zapatistas/México, Conaie/ Equador e Coccaleros/Bolívia) e movimentos camponeses (MST/Brasil), é possível postular que o movimento de renovação da educação popular está indissoluvelmente relacionado com a necessidade de uma nova episteme que supere as perspectivas eurocêntricas.

Logo, partindo deste panorama da EP, nos debruçamos nas reflexões a seguir em um exercício teórico/prático do olhar atento aos desafios e às possibilidades da educação popular constituir-se na escola pública enquanto "cunhas" entre as brechas de democratização e humanização deste território. Para isto, Paludo (2015) afirma que, na atualidade, são desafios da EP, no campo teórico, a construção de protagonismo articulando as dimensões históricas, com base no diálogo entre totalidade e práxis: e, no aspecto prático, a efetiva busca de trabalho coletivo, político e articulado aos movimentos sociais, que vislumbram o desenvolvimento de quatro eixos, sendo eles: a ontologia do ser social, as necessidades humanas, a forma de organização política do Estado capitalista, e as estratégias de resistência e luta.

\section{Escola pública: um terreno de possibilidades}

\begin{abstract}
A demarcação dessa crise da instituição escolar - que não conseguiria mais cumprir a função histórico-social para ela definida nos últimos 200 anos de história do ocidente capitalista - dialoga com uma literatura que define a existência de um mundo pósmoderno que, ao impor outros sentidos à vida econômica e social (portanto, também à vida cultural), coloca a instituição escolar e os sistemas públicos de ensino no centro de uma discussão decisiva. (BARROSO, 2005, p. 1).
\end{abstract}

Abordar a escola pública ${ }^{5}$ implica pensar seu sentido histórico e social. Para Barroso (2005), na discussão do pensamento educacional brasileiro contemporâneo (década de 1980) e o projeto de construção, no interior da conjuntura da "redemocratização", de uma escola pública "popular" houve uma organização e estruturação da instituição escolar do modo que a conhecemos, praticamente universal, e que passa por períodos de ambiguidades e incertezas. Assim, no ocidente capitalista, "o pensamento social que guiou a expansão da escolarização obrigatória em sistemas públicos de ensino estava fundado na certeza de que a apropriação, por todos os cidadãos, de uma cultura 'nacional' e 'universal' era valiosa e necessária” (BARROSO, 2005, p. 1).

$\mathrm{Na}$ atualidade, a proposição seria da escola pública universalizada, laica e neutra, apesar de compreendemos que, no interior da

5. O termo "escola pública" tem sido questionado, pois o termo "escola estatal" seria mais adequado, ao considerarmos a oferta da educação pelo Estado brasileiro (PARO, 2000; SILVA, 2007), uma vez que a escola para ser pública precisaria estar garantindo o acesso à permanência e uma educação de qualidade para todos. No entanto, neste texto, será usado o termo escola pública por acreditarmos que, sendo essa uma instituição em disputa, este termo nos coloca a reflexão do sentido desta para educação e para o projeto de desenvolvimento societário. 
escola, nas políticas e nos programas, reflete-se o contrário, havendo supervisão centralizada para garantir a equidade das unidades entre si; e seus docentes, escolhidos por critérios meritocráticos, de modo a autonomia ser limitada na escolha dos conteúdos, a fim de seguir didáticas apropriadas e classificar/selecionar os alunos.

Nesse período, vinculada à expansão dos sistemas públicos de ensino estava a ideia do "nivelamento das desigualdades de origem", a escola como fonte redentora da ignorância e irracionalidade (BARROSO, 2005). Nessa universalização, a escola vai sendo estruturada naturalmente, insinuando poucos questionamentos quanto a princípios e fundamentos pela sua obviedade.

No Brasil, a organização dos sistemas públicos de ensino ${ }^{6}$ nos leva ao período dos "pioneiros", também atrelados às ideias redentoras da escolarização para todos brasileiros. Até os anos 1920, a escola foi tratada como um instrumento de mobilidade social. Os estratos sociais que detinham o poder econômico e político tinham na educação um distintivo de classe, impulsionando as camadas médias a buscarem a educação como possibilidade de ascensão social, prestígio e integração com as classes dominantes. De acordo com Romanelli (1978), nesse período, a oferta de escola média era embrionária, estando limitada a praticamente algumas iniciativas do setor privado, pois a função educadora na sociedade para os níveis médio e primário inexistia, merecendo atenção do Estado, apenas formalmente. Com a transição da sociedade brasileira agrário-exportadora para urbano-industrial, as estruturas de poder foram redefinidas e surgem relevantes transformações na educação vinculadas à industrialização. Dentre elas, a criação do Ministério da Educação e Saúde, em 1930, e da Universidade, a partir da fusão de várias instituições isoladas de Ensino Superior, dando origem ao sistema nacional de ensino.

O projeto da modernidade educativa no Brasil é materializado nos anos de 1980 e 1990, por meio da crescente oferta de vagas em estabelecimentos públicos de ensino (BARROSO, 2005). Essa universalização do acesso e da ampliação do ensino escolar no início do século XX, não contempla o sentido popular da escola pública e, no final do século $\mathrm{XX}$, entra em crise porque o acesso à escola não garantiu a integração dos excluídos, evidenciando a relação da instituição escola com projeto de sociedade e economia liberal.

Nas últimas décadas, os espaços de reflexão sobre a educação formal têm intensificado a pauta em torno das possibilidades de transformação dos métodos de educação no espaço público. Neste movimento, está enraizada a temática sobre as possibilidades do desenvolvimento do método da educação popular no espaço da escola formal, com maior tensão nas disputas travadas no processo de construção das diretrizes por uma igualdade racial, nas diretrizes da educação do campo e da educação ambiental etc. Processo que perpassa algumas compreensões essenciais em torno da historicidade de ambas as modalidades metodológicas, que, em essência, encontram-se no antagonismo social do modo de produção do sistema capitalista. A começar pela compreensão de formação de seres humanos para o mundo do trabalho; este que, na perspectiva da educação popular, é a própria formação humana e é o marco existencial da história e da transformação dessa historicidade, que entre os muros da escola pública encontrase negada, em prol da formação para o trabalho.

A retomada do conceito de trabalho, que,

6. Esta abordagem encontra-se desenvolvida na dissertação de mestrado "Gestão democrática na escola pública na perspectiva da educação popular do campo: um estudo de caso na E. M. E. F. Dr. Jaime de Faria" (BIERHALS, 2013). 
embora nesse modo de produção se limite à redução do trabalho alienado, na amplitude das práxis populares é ontológico e, por assim dizer, também é criativo, transformador e libertador. Para Mészáros, em Homo fazer, Homo sapiens, o trabalho não pode ser separado em nenhuma atividade humana. E, corroborando com Gramsci (2001 apud MÉSZÁROS, 2008, p. 50), "todo ser humano contribui, de uma forma ou de outra, para a formação de uma concepção de mundo predominante. [...] tal contribuição pode cair nas categorias contrastantes da 'manutenção' e da 'mudança'. Pode não ser apenas uma ou outra, mas ambas simultaneamente".

Assim, o trabalho se materializa enquanto conceito na prática cotidiana da organização da classe trabalhadora e se fortalece no processo educativo pautado nos princípios de uma sociedade de direitos e deveres iguais a toda humanidade. Direitos que, na perspectiva materialista histórica e dialética, não se traduzem na consolidação dos interesses de uma classe, mas se materializam na intencionalidade de construir as condições necessárias à formação de seres genéricos.

Nessa construção, compreende-se uma formação necessariamente articulada com o processo educativo, atrelada aos conhecimentos necessários à leitura de mundo crítica, e que trabalha saberes capazes de compor a clareza de ação e reflexão diante dos condicionamentos de uma sociedade desigual. Além disso, podemos evidenciar, nos avanços demonstrados na caminhada da escola pública, o reflexo nas práticas democráticas embasadas, como já citado, na garantia legal de acesso, permanência e qualidade; para tanto, se constituem as instâncias de protagonismo popular, como: Conselho Escolar (soberano), Círculo de Pais e Mestres, Grêmio Estudantil e a própria gestão da escola eleita democraticamente.

Cabe destacar que as decisões administrativas, pedagógicas e financeiras são endossadas por essas entidades no interior da escola. Queremos dizer que as propostas educativas praticadas, de algum modo, são discutidas na escola, inclusive validadas por atas e documentos que expressam a participação de todos os segmentos em tais discussões. Nesse sentido, fica evidente que a constituição do direito não reflete a prática, pois em grande parte o "protagonismo" da comunidade escolar nem sempre se apresenta enraizado na perspectiva do método de educação popular, em muitos casos ocorrendo a aprovação de decisões e propostas "prontas" que, na prática, não refletem a perspectiva de uma gestão democrática, servindo então, aos ideais hegemônicos.

Com referência à classe de professores, lembramos aqui que currículo, método, formação inicial e continuada etc. são pautas de discussões dos conselhos municipal, estadual e nacional de educação que, em última instância, aprovam as propostas. Lembramos, ainda, dos fóruns de discussão que se apresentam como instâncias de discussões e popularização das propostas a serem aprovadas nas instâncias. Porém, tais estruturas, que deveriam garantir a democratização das tomadas de decisão, parecem desconhecidas de uma maioria tanto no interior da escola quanto na academia, gerando novamente a contradição, pois o espaço democrático de discussão e construção nem sempre é ocupado diretamente pelos protagonistas da educação popular. Esse espaço é representado apenas por uma minoria que impõe a sua concepção de educação, currículo, formação inicial e continuada de professores etc.

O contraponto, ao longo da história do desenvolvimento da escola pública e no interior de sua improdutividade crítica e criativa, é que há alternativas educacionais mais comprometidas com os sujeitos que materializam vida nesse espaço, evidenciando, o movimento complexo que se estabelece nas 
relações de opressão entre a intencionalidade Estatal $^{7}$ e o que fazer do cotidiano educacional.

Assim, esse movimento se fortalece na tomada de consciência dos professores, que se assumem no mundo enquanto classe e enquanto sujeitos políticos, afirmam-se como homens e mulheres que no desequilíbrio entre a realidade social e a proposição ideológica burguesa, desvelam e se desafiam a transformar as correntes estruturais da escola improdutiva. Esse movimento somado à organização popular que também se multiplica na comunidade para além dos muros da escola, problematiza, questiona e combate a historicidade da lógica educacional, encontrando uma possibilidade de fortalecimento de um movimento transformador. Possibilidade que se estrutura na própria ineficácia do método educacional formal. Ineficácia que não se desvela inocentemente, mas que é evidenciada na relação direta da crise gerada nas bases do sistema capitalista, como uma encruzilhada entre as diretrizes outorgadas historicamente, a instituição educacional comprometida com a formação de mão de obra adequada às necessidades do mercado, e as novas necessidades de sustentação do modelo produtivo.

No tocante à classe trabalhadora, tal reorganização tem motivado a formação de uma massa subalterna "diferenciada" - com um mínimo de habilidades que atenda às necessidades da dinâmica industrial -, e exigido do sistema educacional a reformulação do programa que se encontra engessado na hierarquizaçãodosaber, comvistasnaorganização de um processo formativo capaz de consolidar a formação de sujeitos aptos a atender as novas exigências do mercado para a força de trabalho, perpetuando o ciclo imposto à escola pública. Se de um lado tal fragilidade representa, ao longo do processo histórico-social, um fenômeno de mutação do próprio sistema do capital, a contraponto também manifesta possibilidades de resistência propositiva de outra perspectiva dentro e fora do contexto escolar. Pela existência de acúmulos no campo popular, dos movimentos sociais, Paludo (2010, p. 11) afirma que:

O sistema do capital continua cada vez mais avassalador. Os oprimidos, classes populares, estão aí... O que hegemoniza na escola e na sociedade é uma concepção de educação como mercadoria/teoria do capital humano, que é centrada, quase que exclusivamente, na busca individual de um lugar no mercado de trabalho. O que se vê, no campo e na cidade, são pessoas vivendo e tendo que ser em condições absolutamente desumanas. O que Freire propôs e propõe é uma concepção de Educação Popular, isto é, de educação do povo, como prática da liberdade, como Pedagogia da Esperança. O núcleo duro da pedagogia é que ela tem que ser forjada com os oprimidos e não para eles, enquanto seres humanos ou povos que necessitam lutar pela recuperação de sua humanidade.

Nessa perspectiva de educação como prática de liberdade enunciada por Paludo (2010), situam-se algumas das experiências que apontam, ainda que com contradições, as possibilidades de desenvolvimento de práticas da EP no interior da escola pública. Para isso elencamos três significativas experiências, a primeira remete à "Gestão do educador Paulo Freire", da então prefeita de São Paulo, Luiza Erundina de Sousa, filiada à época ao Partido dos Trabalhadores (PT), que implicou em viabilizar o

7. É importante salientar que, quando nos referimos ao Estado, para além de ações de governo, nos retemos à compreensão dele, na perspectiva marxista que o conceitua como uma instituição que se estabelece como um "comitê para gerir os negócios comuns de toda a burguesia" (MARX; ENGELS, 1978, p. 96). Porém, mesmo reconhecendo esses limites, acredita-se que o Estado se constitui na perspectiva de hegemonia e contrahegemonia, entre as quais. segundo Gramsci, cria-se um espaço de concentração da luta de classes. E, neste espaço possibilita-se a mediação de conflitos entre a classe dominante e as bandeiras de luta e resistência dos dominados. 
projeto político pedagógico de sua gestão por meio da reorientação curricular e a formação permanente dos educadores, considerando a relação dialética entre o contexto históricosocial-político e cultural e o currículo. Outra experiência significativa nas linhas da gestão escolar foi a "Escola Cidadã" em Porto Alegre, no Rio Grande do Sul, também na gestão do PT, organizada a partir dos Ciclos de Formação ${ }^{8}$. A adesão aos Ciclos foi efetivada por tomada de decisão das comunidades escolares, com a participação de segmentos, por meio de assembleias, plebiscitos em todas as escolas e comunidades envolvidas. Por fim, a última experiência elencada é a do Movimento dos Trabalhadores Rurais Sem Terra (MST) que, nas práticas educativas desenvolvidas no Instituto de Educação Josué de Castro ${ }^{9}$ (IEJC), em Veranópolis, no Rio Grande do Sul, articulam educação, trabalho, autogestão, autoorganização dos estudantes, cooperativismo popular, soberania alimentar.

Assim, reafirmamos que a intensificação da discussão em torno da escola pública permeada pelos princípios da educação popular constitui-se como proposição, que encontra potencialidade quando inserida em contextos de enfrentamento político e social, estabelecido na maturidade crítica dos sujeitos sociais que constituem a classe trabalhadora, a partir de uma compreensão materialista histórica de que a transformação social passa necessariamente pelo levante da força popular, na certeza de que se os oprimidos conscientes de sua condição constroem e movimentam a força estrutural dessa sociedade, somente eles poderão transformá-la (FREIRE, 1987).

\section{Caminhos desencontrados e o encontro do horizonte: considerações finais}

Perguntando, caminhamos. Vamos refletir, mas vamos caminhar com unidade de ação com os movimentos emancipatórios, para que possamos, de fato, forjar outra perspectiva societária. (Lema Zapatista).

A principal convicção é que só caminhando podemos construir um rumo coletivo e democrático, porém é preciso compreender que, dentre as estradas que nos é permitido trilhar, nem todos os pontos de partida e de chegada estão comprometidos com um novo horizonte social e sim com as possibilidades de reformação do horizonte já estabelecido. Há dificuldades em termos consenso entre os professores e educadores no que diz respeito ao "avanço das utopias de fazer das redes públicas de ensino os espaços privilegiados da desejada escola popular ou transformadora" (BARROSO, 2005, p. 9).

Nessa perspectiva, a crise de sentido da instituição escolar aponta na direção de encontrar saídas políticas e pedagógicas,

$\mathrm{Na}$ refundação enquanto uma escola efetivamente popular - é uma tarefa-desafio ainda em aberto para os educadores. O projeto - aparentemente irrealizável - é construir uma educação pública que seja, ao mesmo tempo, democrática (extensiva a todos, indistintamente) e portadora de uma determinada qualidade, que seja socialmente referenciada e distante da lógica excludente. Uma escola que consiga inserir as novas gerações num mundo inteiramente transformado e distante daquele que originou

8. Para maior aprofundamento ler "Escola Cidadã: Políticas e Práticas", de José Clóvis de Azevedo (2000).

9. "Aprofundar em caminhos para transformação da escola: organização do trabalho pedagógico nas escolas do campo: ensaios sobre complexos de estudo". São Paulo: Expressão Popular, 2015. 
a sua universalização. $\mathrm{O}$ que temos de concreto, como ponto de partida, é aquilo que a instituição escolar é historicamente designada para fazer: a inserção das novas gerações no patrimônio cultural acumulado, na tradição de suas sociedades. (BARROSO, 2005, p.11).

Nesse processo, precisamos ter claro que uma reforma não altera a essência do processo estabelecido, apenas o reorganiza em um movimento de adaptabilidade às exigências temporais. Situação essa que não atende a base formativa do método de educação popular, exatamente por ele estar sustentado no princípio de rompimento com a estabilidade hegemônica, se mobilizando no sentido de garantia do protagonismo popular. Por isso, tal rompimento, que busca abrir novas estradas rumo ao que Marx (1989) propõe como emancipação humana, compreende a necessidade de construir as condições necessárias para que não se recaia no erro de transformação aparente do fenômeno de exploração e alienação, mas que se crie um movimento enraizado em sua essência de mudança.

Por assim acreditar, nos desafiamos a buscar as possibilidades de utilizar estradas já estabelecidas que nos exige a compreensão de que a redução das reflexões sobre as possibilidades de EP na escola pública a um simples dualismo entre sim e não, situa a redução do avanço histórico a um sectarismo dogmático que nega o poder reflexivo, prático e criativo do ser ontológico que mantém viva a veia de transformações no tempo e no espaço vivido.

Então, sentenciar esse processo na complexidade da luta de classes no interior do espaço escolar se configuraria em um processo determinista, e, por isso, propomos avançar nas reflexões sobre a aproximação da EP em uma esfera que constitua prerrogativas para a construção das condições necessárias para o que Freire (1987) chama de inédito viável. Nessa prerrogativa, compreender-se politicamente no mundo - significa desafiar-se em um movimento questionador e crítico, pautado no intenso diálogo teórico e prático sobre as raízes que impulsionam as relações sociais que possam superar os limites que nos constitui, antes mesmo de nossa individualidade, e que nos enraíza enquanto sujeitos sociais.

Ancorar-no-mos apenas no pensamento crítico e em uma ação política emancipatória é insuficiente, pois a EP requer uma pedagogia crítica nos diversos âmbitos de construção das relações humanas, na continuidade que vai do pessoal ao coletivo, às organizações e aos movimentos (GOLDAR, 2014). Dessa maneira, objetivar as brechas dentre as contradições e esferas de mudança significa carregar a intencionalidade da ação educativa e transformadora de forma coerente entre as possibilidades em âmbito particular em conformidade com as possibilidades globais.

Situamos, nesse movimento, um esforço revolucionário no contexto da escola atual, de forma que se possa tomar as decisões de transformações locais sem perder a amplitude das necessidades de transformações globais, redimensionando, assim, as relações de coletividade fundamentadas na transparência, na participação e na individualidade que solidifica o coletivo, atuando sobre as reais contradições e fragilidades que se desenvolvem ao longo do trabalho.

Refletindo sobre essas premissas que emergem no pensar e agir no/do chão da escola, acreditamos que podemos sim buscar materializar a educação popular no espaço público, desde que essa proposta se desenvolva sobre a consciência dos limites que cercam suas potencialidades. Dessa forma, cabe a cada comunidade escolar, no esforço reflexivo, encontrar as premissas capazes de auxiliar na compreensão da complexidade que constitui a teia entre estado, capital privado e sociedade civil. 
Tal compreensão evidencia o espaço da escola pública como território em disputa, de forma que compreender o chão da escola seja também perceber a engrenagem que produz e reproduz a estrutura de nossa sociedade, sendo também o espaço de construção do modelo educativo, contribuinte com a manutenção ou mudança dessa sociedade. A descoberta dessa perspectiva na coletividade da escola parecenos uma síntese importante para reflexão sobre a práxis educativa na escola pública, sua função democrática de decisão, disputa e escolha política e pedagógica.

Nesse sentido, nossas considerações finais encaminham para a importância de situar o trabalho como princípio educativo, a gestão democrática como direito e dever do ato educativo e administrativo no chão da escola. Além disso, é fundamental estabelecer o diálogo como instrumento político capaz de desvelar a realidade, de objetivar a compreensão de sujeitos coletivos e de colocar o conhecimento em movimento prático de tomada de decisão popular.

\section{Referências}

ANTUNES, R. O continente do labor. São Paulo: Boitempo, 2011. 175 p.

BARROSO, G. A construção de uma escola pública "popular": registros de um projeto inconcluso. In: COLÓQUIO INTERNACIONAL PAULO FREIRE, 5., 2005, Recife. Anais... Recife: Editora da UFPE, 2005

BIERHALS, R. Gestão democrática na escola pública na perspectiva da educação popular do campo: um estudo de caso na E. M. E. F. Dr. Jaime de Faria. Porto Alegre/RS, 2013. 138 f. Dissertação (Mestrado em Educação) - Faculdade de Educação, Universidade Federal do Rio Grande do Sul, Porto Alegre, 2013.

FREIRE, P. Pedagogia do oprimido. 17 ed. Rio de Janeiro: Paz e Terra: 1987. 253 p.

FREITAS, L. C. A luta por uma pedagogia do meio: revisitando o conceito. In: PISTRAK, M. A escola-comuna. Tradução de Luiz Carlos de Freitas e Alexandra Marenich. São Paulo: Expressão Popular, 2009. p. 7-108.

GRAMSCl, A. Cadernos do cárcere. v. 2. Tradução de Carlos Nelson Coutinho. 2. ed. Rio de Janeiro: Civilização Brasileira, 2001. 332 p.

FRIGOTTO, G. A produtividade da escola improdutiva. Um (re) exame das relações entre educação e estrutura econômico-social capitalista. São Paulo: Cortez, 2002.

. Trabalho como princípio educativo: por uma superação das ambigüidades. Boletim Técnico do SENAC, Rio de Janeiro, v. 11, n. 3, p. 175-182, set./dez. 1985.

FRIGOTTO, G.; CIAVATTA, M., RAMOS, M. N. (Org.). Ensino médio integrado: concepção e contradições. São Paulo: Cortez, 2005. 176 p. 
GOLDAR, M. Educação popular na América Latina e no Caribe: buscas e desafios para uma alternativa de educação para a transformação social, política, educacional e a educação dos trabalhadores. In: PALUDO, C. (Org.). Campo e cidade em busca de caminhos comuns. Pelotas: Editora da UFPel, 2014. 203 p.

KOSIK, K. Dialética do concreto. 2. ed. Rio de Janeiro, RJ: Paz e Terra, 1995. 230 p.

LEHER, R. Educação popular como estratégia política. In: JANIZE, E; ALMEIDA, M. L. P. (Org.). Educação e movimentos sociais: novos olhares. SP: Alínea, 2007. p. 19-32.

MARX, K. A questão judaica. Tradução de Artur Morão. Lisboa: Edições 70, 1989. Disponível em: $<$ http://www.lusosofia.net/textos/marx_questao_judaica.pdf $>$. Acesso em: 10 jan. 2018.

MARX, K.; ENGELS, F. Manifesto do partido comunista. In: LASKI, H. J. O manifesto comunista de Marx e Engels. 2. ed. Rio de Janeiro: J. Zahar, 1978. 147 p.

MÉSZÁROS, I. A educação para além do capital. 2. ed. São Paulo: Boitempo, 2008. 126 p.

PALUDO, C. Educação popular. In: CALDART, R. et al. (Org.) Dicionário da educação do campo. 2. ed. Rio de Janeiro: Escola Politécnica de Saúde Joaquim Venâncio; São Paulo: Expressão Popular, 2012. p. 280-285.

Educação popular como resistência e emancipação humana. Cadernos CEDES, v. 35, p. 219-238, 2015. Doi: https://doi.org/10.1590/CC0101-32622015723770.

. Metodologia do trabalho popular. In: STRECK, D. R.; REDIN, E.; ZITKOSKI, J. J. (Org.). Dicionário Paulo Freire. 2. ed. Belo Horizonte: Autêntica, 2010. p. 264-265.

PARO, V. H. Gestão democrática da escola pública. São Paulo: Ática, 2000. 141 p.

SILVA, J. C. A escola pública no Brasil: problematizando a questão. Publicatio, Ponta Grossa, v. 15, n. 2, p. 25-32, dez. 2007.

TRIVIÑOS, A. Introdução à pesquisa em Ciências Sociais. São Paulo: Atlas, 1987. 175 p.

VALE, M. Educação popular na escola pública. São Paulo: Cortez, 1996. 111 p.

Submetido em 5 de março de 2018.

Aprovado em 25 de maio de 2018. 